\title{
Leishmania amazonensis em cão com quadro clínico de leishmaniose visceral no Estado do Paraná, Brasil - relato de caso
}

\section{Leishmania amazonensis in dog with clinical diagnosis of visceral leishmaniasis in Paraná State, Brazil - a case report}

\author{
Aline Rafaeli Hoffmann ${ }^{1 *}$; Italmar Teodorico Navarro²; Valdair Elemar Camargo \\ Junior $^{3}$; Eloiza Teles Caldart ${ }^{4}$; Regina Mitsuka Breganó ${ }^{5}$; Patrícia Mendes Pereira ${ }^{6}$
}

\section{Resumo}

As leishmanioses são antropozoonoses que envolvem diversas espécies de Leishmania e hospedeiros, tendo apresentações clínicas variáveis e consideradas de grande importância para a saúde pública. Este artigo descreve um caso de leishmaniose canina causada por Leishmania amazonensis, proveniente da cidade de Cambé, Paraná - Brasil. Este estado é considerado endêmico para a leishmaniose tegumentar americana (LTA) em humanos, porém este é o primeiro relato em cão na região, provocado pela $L$. amazonensis. A caracterização taxonômica da Leishmania foi realizada através da técnica multilocus enzyme electrophoresis (MLEE). Os sinais clínicos foram similares aos observados na leishmaniose visceral como poliartrite e emagrecimento progressivo. Conclui-se que a poliartrite quando relacionada à leishmaniose não pode ser considerada um sinal clínico associado somente a $L$. chagasi, tendo em vista que a $L$. amazonensis também tem esta como uma das suas formas de apresentação. A LTA torna-se um diagnóstico diferencial de poliartrite em cães.

Palavras-chave: Canis familiaris, leishmaniose visceral, poliartrite

\begin{abstract}
Leishmaniasis are antropozoonoses involving various species of Leishmania and hosts, with variable clinical presentations and considered of great importance to public health. This article describes a case of canine leishmaniasis caused by Leishmania amazonensis, from the town of Cambé, Paraná state, Brazil. This state is considered endemic for American cutaneous leishmaniasis (ACL) in humans, but this is the first report in a dog in the region, caused by L. amazonensis. The taxonomic characterization of Leishmania was performed by multilocus enzyme electrophoresis technique (MLEE). Clinical signs were similar to those observed in visceral leishmaniasis as polyarthritis and progressive weight loss. It is concluded that the related polyarthritis when related to leishmaniasis, cannot be considered a clinical sign associated only with L. chagasi in view of the L. amazonensis also has this as one of its presentations. The LTA becomes a differential diagnosis of polyarthritis in dogs.
\end{abstract}

Key words: Canis familiaris, visceral leishmaniasis, polyarthritis

1 Pós Graduando, Dept ${ }^{\circ}$ de Clínicas Veterinárias, Universidade Estadual de Londrina, UEL/DCV, Londrina, PR. E-mail: alinerhoffmann@yahoo.com.br

2 Prof. Dr., Dept ${ }^{\circ}$ de Medicina Veterinária Preventiva, UEL/DMVP, Londrina, PR. E-mail: italmar@uel.br

3 Discente, curso de Medicina Veterinária, UEL/DCV, Londrina, PR. E-mail: camargovaldair@yahoo.com.br

4 Pós Graduando, Dept ${ }^{\circ}$ de Medicina Veterinária Preventiva, UEL/DMVP, Londrina, PR. E-mail: eloiza.vet@gmail.com

5 Prof $^{\mathrm{a}} \mathrm{Dr}^{\mathrm{a}}$, Dept ${ }^{\circ}$ de Ciências Patológicas, Centro de Ciências Biológicas, UEL, Londrina, PR. E-mail: rbregano@uel.br

${ }^{6}$ Prof $^{\mathrm{a}}$ Dr $^{\mathrm{a}}$, Dept ${ }^{\circ}$ de Clínicas Veterinárias, UEL/DCV, Londrina, PR. E-mail: pmendes@uel.br

Autor para correspondência 


\section{Introdução}

As leishmanioses são antropozoonoses consideradas um grave problema de saúde pública, representando um complexo de doenças com importante espectro clínico e diversidade epidemiológica (BRASIL, 2007). A leishmaniose tegumentar americana (LTA) é uma doença caracterizada por lesões de pele, cartilagem e mucosas. A forma de apresentação clínica varia, tanto em humanos como em animais, conforme a espécie de leishmania envolvida e sua interação com o seu hospedeiro (SARIDOMICHELAKIS, 2009).

Até o momento foram identificadas no Brasil seis espécies de Leishmania como causadoras de LTA humana: L. braziliensis, L. guyanensis, L. naiffi, L. shawi, L. lainsoni e L. amazonensis (GONTIJO; CARVALHO, 2003).

A principal forma de transmissão do parasita para o homem e outros hospedeiros mamíferos é vetorial, através da picada de fêmeas de dípteros da família Psychodidae, sub-família Phebotominae, gênero Lutzomya, conhecidos genericamente por flebotomíneos (GONTIJO; CARVALHO, 2003).

A interação do vetor e do meio ambiente urbano é de fundamental importância, visto que a Lutzomyia é um gênero sinantrópico, com alta adaptabilidade a ambientes domésticos, tornando-se um dos fatores mais importantes para a transmissão da doença (GONTIJO; MELO, 2004).

Como não existe um teste diagnóstico que apresente $100 \%$ de especificidade e sensibilidade para tal doença, a confirmação do diagnóstico deve se basear na associação de técnicas parasitológicas, sorológicas e moleculares (LEONTIDES et al., 2002).

As técnicas recomendadas atualmente pelo Ministério da Saúde para o inquérito sorológico canino são a de imunoflorescência indireta (RIFI) e o método de imunoensaio enzimático (ELISA), sendo esta primeira o teste de eleição para inquéritos epidemiológicos, por ser de fácil execução, baixo custo e alta especificidade. O diagnóstico também pode ser feito através da detecção do parasito por cultivo em meios específicos. As formas amastigotas inoculadas em meio de cultura transformam-se em formas promastigotas. O crescimento do parasito demora de três a cinco dias (BRASIL, 2007).

A reação em cadeia da polimerase (PCR) tem sido usada para identificar e amplificar seletivamente sequências de DNA do parasita, permitindo a utilização de vários tipos de tecidos, incluindo medula óssea, biópsias cutâneas, aspirados de linfonodos, sangue, cortes histológicos e também o vetor. As principais desvantagens desta técnica são os custos, pois necessitam de laboratórios bem equipados e a elevada habilidade técnica do profissional (LEONTIDES et al., 2002).

O objetivo deste relato foi descrever um caso de leishmaniose canina causado pela Leishmania amazonensis, com sinais de doença generalizados, predominantemente o quadro visceral, na região norte do estado do Paraná, Brasil.

\section{Relato do Caso}

Em fevereiro de 2011 foi atendido, no Hospital Veterinário da Universidade Estadual de Londrina (HV-UEL), um cão, sem raça definida, macho, cinco anos de idade, médio porte, procedente do município de Cambé, Paraná, com a queixa principal de claudicação nos quatro membros, aumento de volume em articulações há 20 dias, além de emagrecimento progressivo, apesar do apetite normal.

O proprietário afirmou que o animal foi retirado da rua quando filhote e nunca viajou. Soube informar ainda que a mãe deste animal era peri-domiciliada nesta cidade, portanto conclui-se que o cão relatado nasceu neste município.

No exame clínico o paciente apresentava-se magro, apático, pelame opaco, relutância em se locomover, atrofia muscular dos membros pélvicos 
(Figura 1A), crepitação e aumento de volume em articulações do carpo (Figura 1B) e tarso, bilateral, e aumento de volume em joelho esquerdo. As articulações estavam quentes e o paciente reclamava de dor quando manipuladas, constatou-se, portanto uma poliartrite.

Figura 1. Cão sem raça definida, macho, cinco anos de idade, porte médio, atendido no Hospital Veterinário da Universidade Estadual de Londrina devido à poliartrite (2011). A: observa-se posicionamento anormal das articulações do carpo e tarso, atrofia muscular dos membros pélvicos, postura em cifose e magreza; B: Aumento de volume nas articulações do carpo.

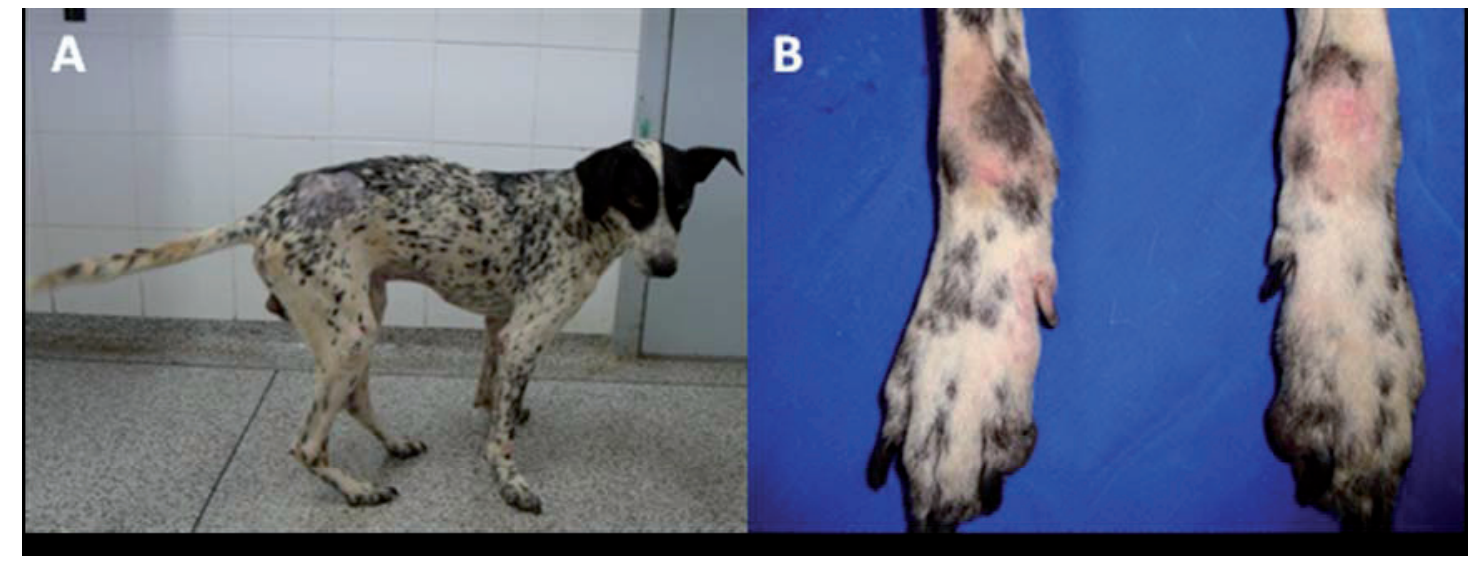

Fonte: Elaboração dos autores.

O proprietário já havia tratado o animal por conta própria com prednisona, na dose de $0,4 \mathrm{mg} / \mathrm{kg} /$ $\mathrm{SID} / 5$ dias, depois $0,2 \mathrm{mg} / \mathrm{kg} / \mathrm{SID} / 3$ dias, juntamente com complexo vitamínico-mineral e relatou pouca melhora durante este tratamento. Quando foi atendido no HV-UEL fazia 13 dias que o animal estava sem medicação.

Inicialmente foram colhidos materiais para a realização dos seguintes exames: hemograma; dosagem de creatinina; proteína total e albumina; radiografia dos carpos; citologia, análise e cultura microbiológica do líquido sinovial; teste para avaliar presença de células de lúpus eritematoso (células LE); sorologia para leishmaniose nos laboratórios do Departamento de Medicina Veterinária Preventiva e HV-UEL, e PCR para erliquiose, em laboratório especializado.

Até a obtenção dos resultados o paciente foi medicado com cloridrato de tramadol $(3 \mathrm{mg} / \mathrm{kg} / \mathrm{PO} /$ TID), prednisona (1,5 mg/kg/PO/BID) e doxiciclina (7,5 mg/kg/PO/BID), devido as suspeitas também de erliquiose, lúpus eritematoso sistêmico e poliartrite imunomediada.

No hemograma foi observado uma leve anemia, hiperproteinemia $(8,1 \mathrm{~g} / \mathrm{dL})$ e hipoalbuminemia $(2,4 \mathrm{~g} / \mathrm{dL})$. Não foram encontradas células LE.

No exame radiográfico foi observada diminuição do espaço articular, reação periosteal moderada em articulação rádio-metacárpica, distensão da cápsula articular deslocando as faces de metacarpo, sugerindo doença articular degenerativa.

O líquido sinovial apresentava uma grande quantidade de leucócitos $\left(162.933 / \mathrm{mm}^{3}\right)$, com predomínio de segmentados (95\%), macrófagos ativados, sinoviócitos degenerados, e cultura microbiológica negativa. $\mathrm{O}$ resultado do PCR para erliquiose foi negativo, enquanto a sorologia foi positiva para Leishmania spp., com titulação 1:160, utilizando-se a reação de imunofluorescência indireta.

Após 21 dias de tratamento o proprietário relatou 
discreta melhora do quadro clínico, já que o animal estava se locomovendo com menos dificuldade, apesar das alterações macroscópicas em articulações permanecerem inalteradas.

O parasita foi isolado da medula óssea em meio bifásico contendo BHI (brain, heart infusion) na fase líquida, enriquecido com $10 \%$ de soro fetal bovino e $5 \%$ de urina humana, e meio ágar sangue na fase sólida. A caracterização taxonômica de Leishmania foi realizada na Coleção de Leishmania do Instituto Oswaldo Cruz (CLIOC) por meio da técnica multilocus enzyme electrophoresis (MLEE) (CUPOLILLO; GRIMALDI JUNIOR; MOMEN, 1994), sendo identificada como L. amazonensis.

O proprietário foi informado que se tratava de uma zoonose, e que o tratamento de animais doentes não é uma medida aceita para o controle da leishmaniose tegumentar ou visceral em cães, devido ao risco de selecionar parasitos resistentes aos fármacos utilizados para o tratamento de casos humanos e de manter animais como reservatórios da doença. Como o quadro clínico do paciente já era avançado, causando dores constantes ao animal, optou-se pela eutanásia, conforme recomendado pelo Ministério da Saúde (BRASIL, 2007). Na necropsia constatou-se a poliartrite e não foram observadas outras alterações dignas de nota.

\section{Discussão}

A LTA é amplamente distribuída no Brasil, ocorrendo em todos os estados, e tem caráter endêmico no estado do Paraná. Das amostras isoladas em cães soropositivos para LTA neste estado, todas foram L. braziliensis (THOMAZSOCCOL et al., 2009), sendo este o primeiro relato de L. amazonensis em cão no estado do Paraná. Outros dois cães em Araçatuba, no estado de São Paulo (TOLEZANO et al., 2007) e dois gatos no estado do Mato Grosso do Sul (DE SOUZA et al., 2005a; SOUZA et al., 2009) também foram infectados pelo mesmo agente.
Em cães a poliartrite quando relacionada à leishmaniose, é atribuída como sinal clínico da leishmaniose visceral causada pela L. chagasi, sendo um dos sinais menos frequentes desta afecção (DE SOUZA et al., 2005b). No caso em questão o paciente apresentava sinais clínicos de leishmaniose visceral, porém causado por L. amazonensis, que é um dos agentes da LTA, semelhante ao encontrado raramente em humanos (COSTA et al., 2009).

Os casos descritos na literatura de cães infectados por L. amazonensis apresentavam sinais viscerais da doença, porém eram provenientes de áreas endêmicas de leishmaniose visceral, cogitandose a possibilidade de infecção concomitante com L. chagasi, mas não foi confirmada esta hipótese (TOLEZANO et al., 2007).

Tendo em vista que no caso em questão também foram observados sinais clínicos viscerais, porém o animal era de uma área endêmica de LTA, e que não há relatos de casos autóctones de leishmaniose visceral no estado do Paraná, podemos sugerir que a $L$. amazonensis pode apresentar aspecto clínico visceral da leishmaniose em cães, apesar de ser originalmente tegumentar.

A lista de doenças que têm sido relatadas coexistindo com a leishmaniose é extensa, incluindo doenças infecçiosas, parasitoses, doenças imunomediadas, endocrinopatias e várias neoplasias. Isto ocorre secundário à imunossupressão causada pela Leishmania ou o inverso também pode ser verdadeiro, por isso é importante investigar os cães que tem alterações clínicas e laboratoriais sugestivas de leishmaniose (SARIDOMICHELAKIS, 2009).

O diagnóstico de leishmaniose foi realizado inicialmente excluindo-se outras causas de poliartrite, como erliquiose e lúpus eritematoso sistêmico, além disso realizou-se a procura do parasita no líquido sinovial e sorologia. Em seguida, tendo a sorologia positiva para Leishmania spp. foi feita a cultura parasitológica com aspirado de medula óssea para isolamento e caracterização do agente pela MLEE, já que um único teste não é o 
suficiente para o diagnóstico preciso (TOLEZANO et al, 2007; LEONTIDES et al., 2002).

As alterações citológicas do líquido sinovial (aumento de neutrófilos, sinoviócitos degenerados) não contribuíram para o diagnóstico da poliartrite causada por leishmaniose, e a não visualização de formas amastigotas no líquido sinovial não exclui a infecção, conforme já demonstrado em estudos anteriores (SILVA, 2009).

No exame físico observou-se poliartrite acometendo principalmente as articulações distais (carpo e tarso) bilateralmente. Na imagem radiográfica dos carpos notou-se reação periosteal moderada, distensão da cápsula articular, diminuição do espaço articular, sugerindo artrite não erosiva com sinais de doença articular degenerativa. Estes achados são semelhantes aos encontrados em quadros de leishmaniose visceral causados por L. chagasi (SANTOS et al., 2006). As alterações radiográficas de cães infectados por Leishmania spp. não são patognomônicas e as lesões articulares não ocorrem exclusivamente devido à presença do parasito, estando relacionada a deposição de imunocomplexos na sinóvia (SILVA, 2009).

Os achados laboratoriais em hemograma e bioquímicos, como anemia, hiperproteinemia e hipergamaglobulinemia são frequentes em animais soropositivos para Leishmania spp., e apesar de serem alterações inespecíficas, colaboram para o diagnóstico (CIARAMELLA; CORONA, 2003).

No Brasil, a LTA é uma doença com diversidade de agentes etiológicos, de reservatórios, de vetores, diferentes padrões de transmissão e um conhecimento ainda limitado sobre alguns aspectos, o que a torna de difícil controle (BRASIL, 2007).

Conclui-se que a poliartrite quando relacionada à leishmaniose não pode ser considerada um sinal clínico associado somente a $L$. chagasi, tendo em vista que a $L$. amazonensis também tem esta como uma das suas formas de apresentação. A LTA tornase um diagnóstico diferencial de poliartrite em cães.

\section{Referências}

BRASIL. Manual de vigilância da leishmaniose tegumentar americana. 2. ed. atual. Brasília: Editora do Ministério da Saúde, 2007. 180 p.

CIARAMELLA, P.; CORONA, M. Canine leishmaniasis: clinical and diagnostic aspects. Compendium on Continuing Education for the Practicing Veterinarian, Yardley, v. 25, n. 5, p. 358-368, 2003.

COSTA, A. A. U. M. L.; SALDANHA, A. C. R.; CORBETT, C. E. P.; BARRAL, A.; BEZERRIL, A. C. R. Alterações ósseas causadas por Leishmania amazonensis na leishmaniose cutânea difusa (LCD). Gazeta Médica da Bahia, Salvador, v. 79, p. 62-69, 2009. Suplemento 3.

CUPOLILLO, E.; GRIMALDI JUNIOR, G.; MOMEN, H. A general classification of New World Leishmania using numerical zymotaxonomy. The American Journal of Tropical Medicine and Hygiene, Deerfield, v. 50, n. 3, p. 296-311, 1994.

DE SOUZA, A. I.; BARROS, E. M. S.; ISHIKAWA, E. A. I.; ILHA, I. M. N.; MARIN, G. R. B.; NUNES, V. L. B. Feline leishmaniasis due to Leishmania (Leishmania) amazonensis in Mato Grosso do Sul State, Brazil. Veterinary Parasitology, Amsterdam, v. 128, n. 1-2, p. 41-45, 2005a.

DE SOUZA, A. I.; JULIANO, R. S.; GOMES, T. S.; DINIZ, S. DE A.; BORGES, A. M.; TAFURI, W. L.; SANTOS, R. DE L. Osteolytic osteomyelitis associated with visceral leishmaniasis in a dog. Veterinary Parasitology, Amsterdam, v. 129, n. 1-2, p. 51-54, 2005 b.

GONTIJO, B.; CARVALHO, M. L. R. Leishmaniose tegumentar americana. Revista da Sociedade Brasileira de Medicina Tropical, Uberaba, v. 36, n. 1, p. 71-80, 2003.

GONTIJO, C. M. F.; MELO, M. N. Leishmaniose visceral no Brasil. Revista Brasileira de Epidemiologia, São Paulo, v. 7, n. 3, p. 338-249, 2004.

LEONTIDES, L. S.; SARIDOMICHELANKIS, M. N.; BILliNIS, C.; KONTOS, V.; KOUTINAS, A. F.; GALATOS, A. D.; MYLONAKIS, M. E. A crosssectional study of Leishmania spp. infection in clinically healthy dogs with polymerase chain reaction and serology in Greece. Veterinary Parasitology, Amsterdam, v. 109, n. 1-2, p. 19-27, 2002.

SANTOS, M.; MARCOS, R.; ASSUNÇÃO, M.; MATOS, A. J. F. Polyarthritis associated with visceral leishmaniasis in a juvenile dog. Veterinary Parasitology, Amsterdam, v. 141, n. 3-4, p. 340-344, 2006. 
SARIDOMICHELAKIS, M. N. Advances in the pathogenesis of canine leishmaniosis: epidemiologic and diagnostic implications. Veterinary Dermatology, Canada, v. 20, n. 5-6, p. 471-489, 2009.

SILVA, A. R. S. Avaliação radiográfica das articulações dos membros locomotores de cães naturalmente acometidos por leishmaniose visceral no município de Araçatuba-SP. 2009. Dissertação (Mestrado em Ciência Animal/Fisiopatologia Clínica e Cirúrgica) Universidade Estadual Paulista Júlio de Mesquita Filho. Campus Araçatuba, Araçatuba.

SOUZA, A. I.; NUNES, V. L. B.; BORRALHO, V. M.; ISHIKAWA, E. A. Y. Domestic feline cutaneous leishmaniasis in the municipality of Ribas do Rio Pardo, Mato Grosso do Sul State, Brazil: a case report. Journal of Venomous Animals and Toxins including Tropical Diseases, Botucatu, v. 15, n. 2, p. 359-365, 2009.
THOMAZ-SOCCOL, V.; DE CASTRO, E. A.; SCHÜHLI, S. G.; CARVALHO, Y.; MARQUES, E.; PEREIRA, E. de F.; ALCANTARA, F. de S.; MACHADO, A. M.; KOWALTHUK, W.; MEMBRIVE, N.; LUZ, E. A new focus of cutaneous leishmaniasis in the central area of Paraná State, southern Brazil. Acta Tropica, Canada, v. 111, n. 3, p. 308-315, 2009.

TOLEZANO, J. E.; ULIANA, S. R. B.; TANIGUCHI, H. H.; ARAÚJO, M. F. L.; BARBOSA, J. A. R.; BARBOSA, J. E. R.; FLOETER-WINTER, L. M.; SHAW, J. J. The first records of Leishmania (Leishmania) amazonensis in dogs (Canis familiaris) diagnosed clinically as having canine visceral leishmaniasis from Araçatuba County, São Paulo State, Brazil. Veterinary Parasitology, Amsterdam, v. 149, n. 3-4, p. 280-284, 2007. 